\title{
Histologia e histoquímica do intestino anterior de tilápia do Nilo (Oreochromis niloticus) alimentadas com dietas contendo silagem de peixe
}

\author{
Histology and histochemical the medium intestine in Nile tilapia (Oreochromis niloticus) fed \\ diets with fish silage
}

\author{
Claucia Aparecida HONORATO ${ }^{1}$; Claudinei da CRUZ²; Dalton José CARNEIRO³; Márcia Rita \\ Fernandes MACHADO ${ }^{4}$
}

\begin{abstract}
${ }^{1}$ Faculdade de Ciências Biológicas e da Saúde do Centro Universitário da Grande Dourados, Dourados - MS, Brasil ${ }^{2}$ Núcleo de Estudos e Pesquisas Ambientais em Matologia da Faculdade de Ciências Agrárias e Veterinárias da Universidade Estadual Paulista, Jaboticabal - SP, Brasil

${ }^{3}$ Laboratório de Nutrição de Organismos Aquáticos do Departamento de Zootecnia da Faculdade de Ciências Agrárias e Veterinárias da Universidade Estadual Paulista, Jaboticabal - SP, Brasil

${ }^{4}$ Departamento de Morfologia e Fisiologia Animal da Faculdade de Ciências Agrárias e Veterinárias da Universidade Estadual Paulista, Jaboticabal - SP, Brasil
\end{abstract}

\begin{abstract}
Resumo
O objetivo deste trabalho foi avaliar a histologia e a histoquímica do intestino anterior de tilápia do Nilo alimentadas com dietas contendo farinha de peixe ou silagem de peixe como fonte de proteína de origem animal. A espessura da vilosidade intestinal dos peixes alimentados com silagem fermentada de resíduo de tilápia foi influenciada pelos teores proteicos, independente das proporções de proteína de origem animal das dietas. Observou-se que a variação da intensidade de secreção de glicoproteínas pelas células caliciformes está diretamente ligada com o tipo de dieta fornecida aos animais. O intestino médio de Oreochromis niloticus apresentou diferenças no padrão de secreção de muco glicoproteico neutro, glicoproteínas ácidas e glicoconjugados, dependendo da origem da proteína e da porcentagem utilizada na dieta, demonstrando que esta espécie pode adaptar seu sistema de secreção para a proteção do aparelho digestório durante a absorção de diferentes fontes proteicas.
\end{abstract}

Palavras-chave: Oreochromis niloticus. Histologia do intestino. Silagem de peixe.

\begin{abstract}
This work was carried out to evaluate the action of the fermented fish silage and fish meal in the histochemical of the middle intestine of $O$. niloticus. A great epithelium intestinal was present in fishes fed with fish silage, independent of the animal origin protein proportions in diets. It was observed that the variation of the goblet cells secretion glicoproteic intensity is linked directly to the diet supplied to animals. The middle intestine of Oreochromis niloticus showed differences in the neutral mucus glicoproteic, acid glicoproteic and glicoconjugated secretion pattern, depending on the protein origin and the percentage used in the diet, demonstrating that this species can adapt its secretion system for the protection of the digesting apparatus during the absorption of different protein sources.
\end{abstract}

Keywords: Oreochromis niloticus. Histology of intestine. Fish silage.

\section{Introdução}

O processamento de peixe produz diariamente uma grande quantidade de resíduos que gera problemas de poluição ambiental, sendo fundamental o processamento destes subprodutos para diminuir o impacto ambiental ${ }^{1}$. Uma alternativa para o aproveitamento de resíduo de pescado é a sua transformação em silagem de peixe para posterior utilização como fonte de proteína na alimentação animal ${ }^{1,2,3}$.
A utilização de resíduos para produção de silagem

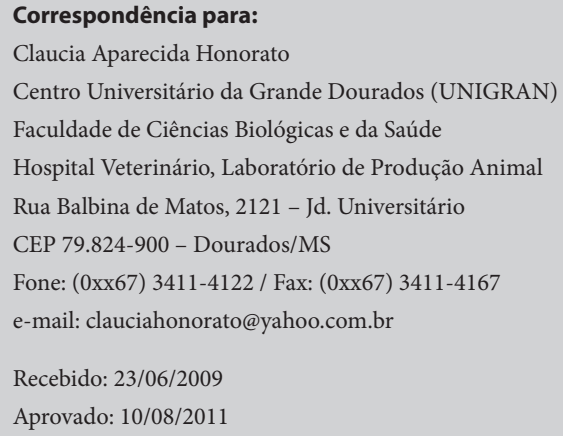


de peixe é vantajoso por ser um processo simples e econômico, o que o torna o produto competitivo no mercado $^{1}$. A silagem de peixe como ingrediente nas dietas para organismos aquáticos, demonstrou-se como proteínas de boa qualidade, elevada digestibilidade $^{4,5}$ e altamente hidrolisada ${ }^{6}$, quando comparada com a farinha de peixe que atualmente é a principal fonte de proteína de origem animal para espécies aquáticas.

A avaliação de novos ingredientes para alimentação animal depende primeiramente das respostas zootécnicas dos animais alimentados com estes produtos ${ }^{7}$. As diferenças no desempenho dos peixes podem ser atribuídas às diferenças interespecíficas, das características de seus tratos digestórios e à eficiência com que o alimento ingerido é capaz de ser digerido e assimilado. A habilidade dos peixes em processar os alimentos é fundamental ao seu desenvolvimento e depende da estrutura do epitélio e das vilosidades intestinais, do perfil enzimático de seu canal alimentar e de sua capacidade adaptativa ${ }^{8}$.

$\mathrm{Na}$ tentativa de aperfeiçoar o aproveitamento dos ingredientes ingeridos, os peixes apresentam capacidade de adaptação dos processos digestivos, tais como: perfil e secreção enzimáticos; absorção e transporte de nutrientes. O estudo morfológico revela o desempenho no processo digestivo, absortivo e metabólico dos diferentes animais ${ }^{9}$, além de ser uma barreira seletiva que permite absorção de nutrientes e exclui muitas substâncias tóxicas ${ }^{10}$ e revela as diferentes adaptações do trato digestório em função a dieta ofertada $^{11,12}$. Portanto, o estudo histológico é essencial para a tomada de decisão quanto ao tipo de fonte de alimento que pode ser recomendada para alimentação de peixes ${ }^{13,14}$.

O objetivo deste trabalho foi avaliar a ocorrência de possíveis alterações histológicas no intestino anterior de tilápia do Nilo alimentadas com dietas contendo silagem fermentada de resíduo de tilápia ou farinha de peixe como fonte de proteína de origem animal.

\section{Material e Método}

O experimento foi conduzido no Laboratório de Nutrição de Organismos Aquáticos do Centro de Aqüicultura da UNESP e as análises histológicas no setor de técnicas morfológicas do Departamento de Morfologia e Fisiologia Animal da FCAV/UNESP, Campus de Jaboticabal.

Para a produção de silagem fermentada, foram utilizados resíduos de filetagem de tilápia (cabeça, vísceras, restos de musculatura, espinhas, pele, escamas e nadadeiras), previamente moídos, e adicionados 15\% $(\mathrm{p} / \mathrm{p})$ de melaço de cana-de-açúcar, $5 \%(\mathrm{p} / \mathrm{p})$ de Lactobacillus plantarum e 0,25\% (v/p) de ácido sórbico ${ }^{3}$. Esta mistura foi armazenada por 30 dias.

Foram confeccionadas doze dietas com três níveis de proteína bruta $(20,24$ e $28 \%)$, duas proporções de proteína de origem animal ( $1 / 4$ ou $1 / 2)$, duas fontes de proteína (farinha de peixe - FP ou a silagem fermentada de resíduo de tilápia- SP). As dietas (Tabela 1) foram denominadas como:

$$
\begin{aligned}
& \text { D01 - 20\%PB 1/4 FP; } \quad \text { D04 - 20\%PB } 1 / 2 \mathrm{FP} \text {; } \\
& \text { D02 - 24\%PB } 1 / 4 \text { FP; } \quad \text { D05 - 24\%PB } 1 / 2 \text { FP; } \\
& \text { D03 - 28\%PB } 1 / 4 \text { FP; } \quad \text { D06 - 28\%PB } 1 / 2 \text { FP; } \\
& \text { D07 - 20\%PB 1/4 SP; } \quad \text { D } 10 \text { - 20\%PB 1/2 SP; } \\
& \text { D08 - 24\%PB } 1 / 4 \text { SP; } \quad \text { D11 - 24\%PB } 1 / 2 \text { SF; } \\
& \text { D09 - 28\%PB } 1 / 4 \text { SP; } \quad \text { D12 - 28\%PB } 1 / 2 \text { SP }
\end{aligned}
$$

As dietas foram peletizadas em máquina de moer carnes do Centro de Aquicultura da UNESP e posteriormente, os pellets foram secos e conservados em freezer para o fornecimento durante o período experimental. $\mathrm{O}$ arraçoamento dos peixes foi à vontade, duas vezes ao dia (manhã e tarde) em pequenas quantidades até a saciedade aparente, para que a quantidade fornecida fosse considerada a consumida.

Para a realização do ensaio biológico foram utilizados 360 alevinos de tilápia com o peso médio inicial de 1,17 $\pm 0,05$ g distribuídos em 36 aquários com ca- 
Tabela 1 - Formulação e composição das dietas experimentais

\begin{tabular}{|c|c|c|c|c|c|c|c|c|c|c|c|c|}
\hline Ingredientes (\%) & D01 & D02 & D03 & D04 & D05 & D06 & D07 & D08 & D09 & D10 & D11 & D12 \\
\hline Farinha de peixe & 8,3 & 10,0 & 11,6 & 16,6 & 20,0 & 23,3 & - & - & - & - & - & - \\
\hline Silagem de peixe & - & - & - & - & - & - & 11,1 & 13,3 & 15,5 & 22,1 & 26,5 & 31,0 \\
\hline Milho moído & 47,0 & 36,5 & 25,9 & 50,9 & 60,7 & 31,3 & 46,9 & 52,5 & 41,4 & 52,2 & 51,7 & 40,8 \\
\hline Farelo de soja & 13,3 & 22,0 & 30,6 & 1,7 & 12,9 & 14,3 & 14,7 & 27,7 & 36,4 & 5,0 & 14,1 & 20,6 \\
\hline Farelo de trigo & 25,0 & 25,0 & 25,0 & 25,0 & 0,2 & 25,0 & 21,3 & - & - & 15,0 & 2,0 & 2,0 \\
\hline Quirera de arroz & 5 & 5 & 5 & 5 & 5 & 5 & 5 & 5 & 5 & 5 & 5 & 5 \\
\hline Óleo de soja & 0,6 & 0,9 & 1,2 & 0,1 & 0,5 & 0,4 & 0,4 & 0,9 & 1,1 & - & - & - \\
\hline Suplemento vitamínico ${ }^{\underline{1} /}$ & 0,4 & 0,4 & 0,4 & 0,4 & 0,4 & 0,4 & 0,4 & 0,4 & 0,4 & 0,4 & 0,4 & 0,4 \\
\hline Suplemento Mineral $2 /$ & 0,3 & 0,3 & 0,3 & 0,3 & 0,3 & 0,3 & 0,3 & 0,3 & 0,3 & 0,3 & 0,3 & 0,3 \\
\hline \multicolumn{13}{|l|}{ Composição Calculada ${ }^{3 /}$} \\
\hline Matéria seca (\%) & 92,6 & 92,3 & 92,0 & 93,2 & 93,0 & 92,9 & 93,3 & 93,1 & 93,0 & 94,4 & 94,7 & 95,0 \\
\hline Proteína bruta (\%) & 20 & 24 & 28 & 20 & 24 & 28 & 20 & 24 & 28 & 20 & 24 & 28 \\
\hline Extrato etéreo (\%) & 4,5 & 4,5 & 4,5 & 4,5 & 4,5 & 4,5 & 4,5 & 4,5 & 4,5 & 4,9 & 4,7 & 4,6 \\
\hline Energia bruta $\left(\mathrm{kcal} \cdot \mathrm{kg}^{-1}\right)$ & 4219 & 4261 & 4303 & 4182 & 4216 & 4251 & 4209 & 4249 & 4289 & 4184 & 4202 & 4230 \\
\hline
\end{tabular}

1/ Composição do suplemento mineral para 1 kg de ração: Ferro 1500 mg, Cobre 5000 mg, Iodo 500 mg, Manganês 17000 mg, Zinco $12000 \mathrm{mg}$, Selênio $70 \mathrm{mg}$, veículo 1000 g. ㄹ Composição do suplemento vitamínico para 1 kg de ração: Vitamina A 12000 UI, Vitamina D, 1500 UI, Vitamina E 50 mg, Vitamina K 4 mg, Vitamina B 7 mg, Ácido Pantotênico 60 mg, Ácido. Nicotínico 120 mg, Cloreto de Colinå $600 \mathrm{mg}$, Metionina $700 \mathrm{mg}$, veículo $1000 \mathrm{~g}$. 解 Composição calculada com base nos dados obtidos em análises realizadas no Laboratório de Nutrição de Organismos Aquáticos do CAUNESP, Jaboticabal, segundo AOAC (2000).

D01 - 20\% PB 1/4 FP; D02 - 24\% PB 1/4 FP; D03 - 28\% PB 1/4 FP; D04 - 20\% PB 1/2 FP; D05 - 24\% PB 11/2 FP; D06 - 28\% PB 1/2 FP; D07 - $20 \%$ PB $1 / 4$ SP; D08 - 24\% PB 1/4 SP; D09 - 28\% PB 1/4 SP; D10 - 20\% PB 11/2 SP; D11 - 24\% PB 1/2 SF; D12 - $28 \%$ PB 1/2 SP

pacidade de $150 \mathrm{~L}$, abastecidos continuamente com água proveniente de poço artesiano, com renovação de aproximadamente 20 vezes ao dia e aeração constante, por um período de 75 dias.

No final do período experimental (75 dias), todos os peixes foram anestesiados em benzocaína (100 $\mathrm{mg} / \mathrm{L}$ ) até completa perda dos sentidos para a biometria e abate em gelo. Para as análises histológicas foram separados nove exemplares de cada tratamento para a retirada de amostras do intestino anterior. Posteriormente, as amostras foram fixadas em solução de Bouin, por 24 horas. Após a fixação, procedeu-se à lavagem em álcool $70 \%$ para desidratação em série alcoólica crescente, diafanização em série de xilóis, inclusão em Histosec e cortados em espessura variando entre 5 a $7 \mu \mathrm{m}$ de espessura. Para cada tratamento (dieta experimental) foram confeccionadas três lâminas por peixe, com total de 27 lâminas por tratamento.

A coloração das lâminas foi realizada pela técnica Hematoxilina - Eosina. Para realização da histoquí- mica utilizaram-se os métodos de PAS/H (Ácido periódico de Shiff), Alcian-Blue PAS, Alcian-Blue pH 0,5 e pH 2,5. Foi realizada a análise de sete secções por lâmina. $\mathrm{O}$ material foi analisado e fotodocumentado em fotomicroscópio Axioskop- Zeiss. Foi realizada a comparação visual da altura das vilosidades intestinais dos peixes submetidos a distintas dietas experimentais. As comparações foram realizadas agrupando os tratamentos em três classes de altura denominadas de pequena, mediana e alta.

O experimento foi conduzido em delineamento inteiramente casualizado (DIC), com doze tratamentos em esquema fatorial $3 \times 2 \times 2$, correspondendo a três níveis de proteína bruta (20, 24 e 28\%), duas proporções de proteína de origem animal ( $1 / 4$ ou $1 / 2$ ), duas fontes de proteína (farinha de peixe - FP ou a silagem fermentada de resíduo de tilápia- SP) nas dietas experimentais, com três repetições. Quando a análise de variância mostrou diferenças significativas entre tratamentos $(P$ $<0,05)$, as médias foram comparadas pelo teste Tukey, 
realizados no Statistical Analysis System (SAS Intitule Inc., version 6.12, 1999) ${ }^{15}$.

\section{Resultados}

A qualidade da água apresentou as médias de oxigênio dissolvido de $5,70 \pm 0,2 \mathrm{mg}$ de $\mathrm{O}_{2} \mathrm{~L}^{-1}$, de temperatura de $29,27 \pm 1,20^{\circ} \mathrm{C}, \mathrm{pH}$ de $7,95 \pm 0,03$ e condutividade de 127,17 $\pm 0,04 \mu \mathrm{s} / \mathrm{cm}$.

O ganho de peso dos peixes durante o período experimental foi $17,13 \pm 4,18$. Os peixes alimentados com as dietas contendo farinha de peixe apresentaram o ganho em peso de 20,3 g superior aos que receberam a dieta contendo silagem de peixe $(13,9 \mathrm{~g})$ como fonte de proteína de origem animal (POA). Os níveis de proteína bruta e proporção de proteína de origem animal apresentaram interação, sendo que os peixes alimentados com a dieta contendo $24 \%$ PB com $1 \frac{1}{2}$ POA (D05 e D11) independente da proveniência da fonte de POA (silagem de peixe ou farinha de peixe) apresentaram as maiores médias de ganho em peso (Figura 1).
O intestino anterior de tilápia do Nilo caracteriza-se por apresentar quatro camadas: a mucosa, a submucosa, a muscular e a serosa. A camada mucosa éconstituída por epitélio cilíndrico simples com borda em escova e células caliciformes, com lâmina própria contendo linfócitos intraepiteliais; a submucosa é formada por células, fibras colágenas e vasos sanguíneos; a camada muscular, de músculo liso em disposição circular e externamente à camada serosa, que é caracterizada por tecido conjuntivo e células pavimentosas. Estas estruturas não apresentaram diferenças na tilápia do Nilo submetidas às dietas experimentais (Figura 2).

A mucosa exibiu um epitélio prismático simples composto por enterócitos entremeados por células caliciformes PAS (positivo), AB (positivo) em $\mathrm{pH}$ 0,5 e 2,5 e PAS/AB (positivo), indicando a secreção de glicoproteínas neutras e glicoproteínas ácidas sulfatadas e carboxiladas e glicoconjugadas. A submucosa apresentou tecido conjuntivo frouxo PAS (positivo). A camada muscular apresentou uma camada interna

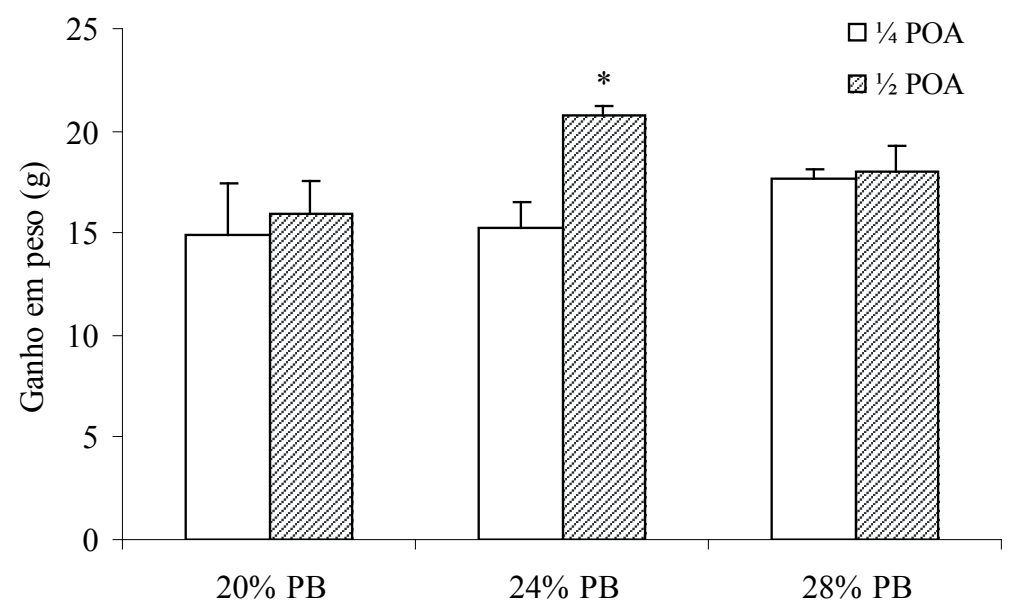

Figura 1 - Ganho em peso de tilápia do Nilo (Oreochromis nilóticos), interação entre os fatores níveis de proteína $(\% \mathrm{~PB})$ e proporção de proteína de origem animal (POA). Valores expressos em média $(n=20) \pm$ D.P. Níveis de proteína bruta $(20,24$ e $28 \%$ $\mathrm{PB})$ e proporção de proteína de origem animal na dieta $(1 / 4 \mathrm{e}$ $1 / 2$ POA). ${ }^{*}$ ) diferença estatística. 24\% PB contendo $1 / 2$ POA corresponde à dieta D05 e D11 

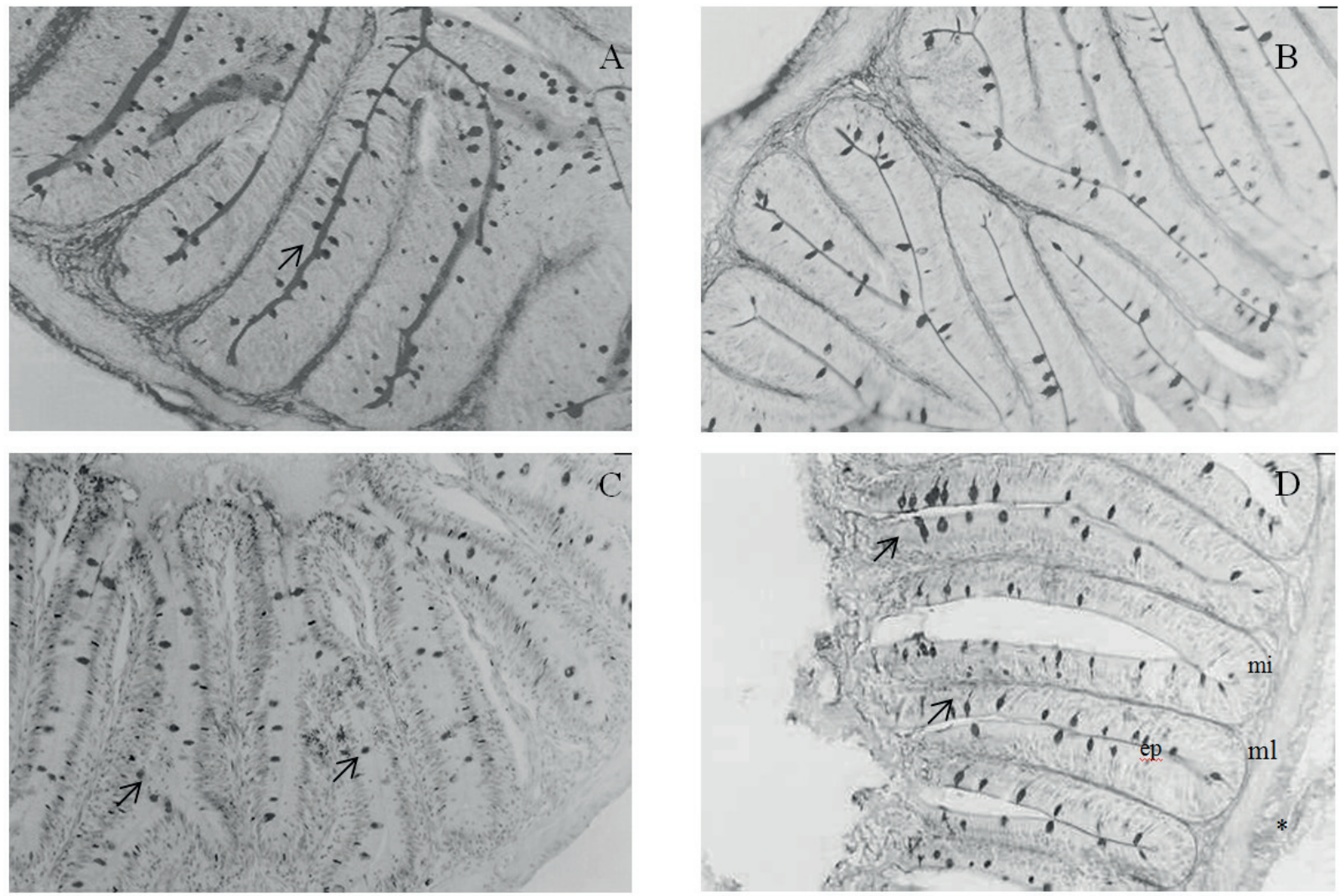

Figura 2 - Foto micrografia de intestino anterior de juvenis de tilápia do Nilo (Oreochromis niloticus). (A) D01 20\% PB 1/4 FP, PAS/H células caliciformes (seta), (B) D05 - 24\% PB 1/2 FP, PAS/H, (C) D10- 20\% PB 1/2 SP, $\mathrm{AB}$ pH 0,5 células caliciformes AB positiva (seta), (D) D12 - 28\% PB 1/2 SP, PAS/AB muscular longitudinal $(\mathrm{ml})$, camada muscular interna $(\mathrm{mi})$, membrana serosa $\left.{ }^{*}\right)$, epitélio da mucosa (ep), células caliciformes glicoconjugadas (seta). (X 400)

com fibra muscular lisa orientada circularmente e outra externa com fibras orientadas longitudinalmente.

Observou-se que a variação da intensidade de secreção de glicoproteínas pelas células caliciformes apresentou-se diretamente correlacionada com o tipo de dieta ofertada aos animais. A secreção de glicoproteínas ácidas e glicoconjugadas (AB/PAS) apresentaram o mesmo padrão para os peixes que receberem as dietas D01, D03 e D04 (contendo farinha de peixe) e os peixes que se alimentaram com as dietas D07, D09 e D10 (contendo silagem de peixe). Observou-se que a intensidade de reação da secreção glicoconjugada (AB/PAS) nos animais alimentados com dietas contendo silagem de peixe (D07, D09 e D10) foi superior quando comparada aos demais tratamentos.
As células caliciformes produtoras de glicoproteínas ácidas $(\mathrm{AB} \mathrm{pH}$ 0.5, $\mathrm{pH}$ 2.5) e glicoconjugadas ( $\mathrm{AB} /$ PAS) apresentaram baixa intensidade de reação, enquanto que as secretoras de muco glicoproteico (PAS) e glicoproteínas glicoconjugadas (AB/PAS) apresentaram intensidade alta de reação nos peixes alimentados com as dietas D08 e D12, ambas contendo silagem de peixe como fonte de POA (Tabela 2).

Os peixes alimentados com a dieta D05 e D11, apesar da diferença na fonte de POA utilizada, farinha de peixe e silagem de peixe, respectivamente, apresentaram secreções semelhantes de muco glicoconjugado (AB/PAS). A secreção de glicoproteínas ácidas ( $\mathrm{AB}$ pH $0.5 ; 2.5)$ e neutra (PAS) revelou-se de intensidade fraca para os peixes alimentados com as 
Tabela 2 - Altura das vilosidades intestinais e histoquímica das células caliciformes do intestino médio de juvenis de tilápia do Nilo (Oreochromis niloticus) submetidos às dietas experimentais

\begin{tabular}{|c|c|c|c|c|c|c|c|c|c|c|c|c|c|}
\hline \multirow{2}{*}{ Dietas } & \multirow{2}{*}{ Altura } & \multicolumn{3}{|c|}{ AB/PAS } & \multicolumn{3}{|c|}{ AB pH 2,5 } & \multicolumn{3}{|c|}{ AB pH 0,5} & \multicolumn{3}{|c|}{ PAS } \\
\hline & & $\mathrm{N}$ & A & C & $\mathrm{N}$ & A & $\mathrm{C}$ & $\mathrm{N}$ & A & $\mathrm{C}$ & $\mathrm{N}$ & A & C \\
\hline D 01 & * & + & + & ++ & - & + & - & - & + & - & +++ & - & - \\
\hline D 02 & $* *$ & + & ++ & ++ & - & + & - & - & + & - & ++ & - & - \\
\hline D 03 & $* *$ & ++ & - & ++ & - & ++ & - & - & +++ & - & ++ & - & - \\
\hline D 04 & * & + & + & + & - & ++ & - & - & ++ & - & ++ & - & - \\
\hline D 05 & $* *$ & +++ & +++ & + & - & +++ & - & - & +++ & - & +++ & - & - \\
\hline D 06 & $* *$ & + & ++ & ++ & - & +++ & - & - & +++ & - & +++ & - & - \\
\hline D 07 & * & ++ & + & +++ & - & ++ & - & - & ++ & - & +++ & - & - \\
\hline D 08 & $* * *$ & ++ & + & + & - & ++ & - & - & ++ & - & +++ & - & - \\
\hline D 09 & $* *$ & + & + & + & - & + & - & - & + & - & ++ & - & - \\
\hline D 10 & * & + & - & + & - & + & - & - & + & - & + & - & - \\
\hline D 11 & $* * *$ & ++ & + & + & - & ++ & - & - & ++ & - & +++ & - & - \\
\hline D 12 & $* *$ & + & + & ++ & - & ++ & - & - & ++ & - & +++ & - & - \\
\hline
\end{tabular}

Altura das vilosidades intestinais: ${ }^{\star}$ (pequena), ${ }^{* *}$ (mediana) $\mathrm{e}^{* * *}$ (alta)

Reações: Neutra (N); Ácida (A); Conjugada (C).

Intensidade da reação positiva: $(+)$ fraca; $(++)$ intermediária; $(+++)$ forte; $(-)$ sem reação

dietas contendo silagem de peixe (D07, D08, D09, D10, D11 e D12) (Tabela 2).

A visualização dos cortes histológicos demonstrou que a altura das vilosidades intestinais foi influenciada principalmente pela fonte de POA utilizada nas dietas. Nos peixes alimentados com dietas contendo farinha de peixe como fonte de POA não houve alteração na altura do epitélio intestinal. Os peixes alimentados com dietas contendo silagem de peixe apresentaram diferentes classificações de altura do epitélio intestinal. Os peixes alimentados com a dieta D08 e D11 apresentaram a altura das vilosidades intestinais classificada como alta.

\section{Discussão}

A qualidade da água manteve-se dentro dos padrões para o cultivo de peixes tropicais ${ }^{16}$, proporcionando o bem-estar e qualidade para sua criação durante o período experimental. $\mathrm{O}$ ganho de peso inferior dos peixes alimentados com as dietas contendo silagem de peixe como fonte proteica pode ser atribuído à presença de substâncias como aminoácidos livres, geradas durante o processo de ensilagem ${ }^{17}$, que podem não ser aproveitados eficientemente por falta de estrutura de absorção ${ }^{14,18}$.
A silagem de peixe na alimentação de tilápia do Nilo demonstrou alterações do trato digestório, que são indicativos de adaptações do trato digestório para melhorar a capacidade de utilização de nutrientes. Alguns trabalhos vêm demonstrando a adaptação morfológica do intestino frente às variações nutricionais para o Piaractus mesopotamicus ${ }^{18}$, Ictalurus punctatus ${ }^{13}, \mathrm{Ra}$ chycentron canadum ${ }^{14}$, S. aurata ${ }^{5}$, Pagrus pagrus ${ }^{19}$. Porém, ainda são muito incipientes os dados que correlacionam alimentação e adaptações histológicas do trato gastro-intestinal de organismos aquáticos ${ }^{9}$.

A estrutura da mucosa intestinal está relacionada com os processos fisiológicos de digestão e absorção, e as regiões de pregas mais complexas estariam envolvidas nos processos absortivos devido ao aumento da área efetiva para absorção de nutrientes ${ }^{20}$. O aumento da altura das vilosidades intestinais dos peixes alimentados com as dietas contendo silagem de peixe como fonte de POA pode ser atribuído à estratégia de melhorar a absorção dos nutrientes, que já se encontravam hidrolisados devido o processo de ensilamento da massa de resíduo ${ }^{17,21}$.

A adaptação da altura das vilosidades intestinais superior dos peixes submetidos a dietas contendo si- 
lagem de peixe pode estar associada às características de um produto liquefeito e hidrolisado. Para tilápia do Nilo, a silagem de peixe resulta em aumento do coeficiente de digestibilidade da proteína e da energia em comparação a farinha de peixe $e^{4}$.

As alterações morfológicas no trato digestório também são observadas no intestino anterior de Rachycentron canadum submetidos a dietas com diferentes fontes de proteína ${ }^{14}$. A utilização de fontes de concentrado proteico de soja e farelo de soja na alimentação de Onchorinchus mykiss e do Piaractus mesopotamicus acarretou em aumento da camada de absorção das duas espécies ${ }^{18}$. Em controvérsia, o uso de fontes de soja (extrato solúvel de soja e extrato concentrado de soja) e de glúten (glúten de milho e glúten de trigo), como fonte proteica não modificou a estrutura histológica do intestino de bacalhau do Atlântico ${ }^{22}$. A altura das vilosidades intestinais está associada ao processo de absorção de nutrientes assim como a capacidade enzimática, responsável pelo processo digestivo ${ }^{23}$.

A digestão intestinal depende da secreção de substâncias glicoproteicas das células caliciformes, da ação proteolítica do suco pancreático e também da digestão intracelular, que está associada à presença de glândulas gástricas ${ }^{24}$. A presença de células caliciformes no intestino de peixes está relacionada a diferentes condições

\section{Referências}

1.BOSCOLO, W. R.; HAYASHI, C.; MEURER, F.; FEIDEN, A.; WOLFF, L. Desempenho e características de carcaça de machos revertidos de tilápia do Nilo (Oreochromis niloticus), linhagem tailandesa e comum, nas fases iniciais e crescimento. Revista Brasileira de Zootecnia, v. 30, n. 5, p. 1391-1396, 2001

2. SECCO, E. M.; STÉFANI, M. V.; VIDOTTI, R. M. Substituição da farinha de peixe pela silagem de peixe na alimentação de girinos de rã touro (Rana catesbiana). Ciência Rural, v. 32, n. 3, p. 505-509, 2002.

3. VIDOTTI, R. M.; VIEGAS, E. M. M.; CARNEIRO, D. J. Amino acid composition of processed fish silage using different raw materials. Animal Feed Science and Technology, v. 105, n. 1/4, p. 199-204, 2003.

4. OLIVEIRA, M. M.; PIMENTA, M. E. S. G.; PIMENTA, C. J.; CAMARGO, A. C. S.; FIORINI, J. E.; LOGATO, P. V. R. Digestibilidade e desempenho de alevinos de tilápia do Nilo (Oreochromis niloticus) alimentados com dietas contendo diferentes níveis de silagem ácida de pescado. Ciência Agrotecnologia, v. 30, n. 6, p. 1196-1204, 2006. de alimentação e à proteção contra a atividade bacteriana $^{25}$, a proteção do epitélio (fluxo laminar) contra o alimento proveniente do estômago, rico em enzimas digestivas e com $\mathrm{pH}$ acentuadamente ácido ${ }^{8,26}$. A secreção das células caliciformes foi influenciada pela fonte de proteína da dieta, o que pode ser atribuído às características do produto ensilado. A acidificação da dieta contendo silagem de peixe refletiu em redução da atividade proteolítica dos intestinos de truta arco-íris (Salmo gairdneri $)^{21}$, o que consequentemente alterou a estrutura de digestão e absorção.

Tilápias do Nilo alimentadas com as dietas contendo silagem fermentada de resíduo de peixe demonstram respostas de alterações nas estruturas morfológicas e na secreção, com a finalidade de melhorar o aproveitamento do alimento, tornando-a um alimento viável a ser utilizado como fonte de proteína de origem animal.

\section{Conclusão}

Os resultados indicam que a utilização de silagem de resíduo de peixe em dietas para tilápia do Nilo proporcionou alterações histológicas benéficas que refletiram em maior desenvolvimento dos peixes. Conclui-se que a silagem de resíduo de peixe é um alimento que pode ser utilizado em dietas para tilápia do Nilo.

5. WASSEF, E. A.; WAHBY, O. M.; SAKR, E. M. Effect of dietary vegetable oils on health and liver histology of gilthead seabream (Sparus aurata) growers. Aquaculture Research, v. 38 , n. 8, p. 852-861, 2007.

6. ESPE, M.; RAA, J.; NJAA, L. R. Nutritional value of stored fish silage as a protein source for young rats. Journal of Science Food and Agriculture, v. 49, n. 3, p. 259-270, 1989.

7.BENGSTON, D. A. A comprehensive program for the evaluation of artificial diets. Journal World Aquaculture Society, v. 24, p. 285-293, 1993.

8. KUPERMAN, B. I.; KUZ'MINA, V. V. The structure of the intestinal epithelium in fish with different types of feeding. Journal Fish Biological, v. 44, n. 2, p. 181-193, 1994.

9. LUNDSTEDT, L. M. Aspectos adaptativos dos processos digestivo e metabólico de juvenis de pintado (Pseudoplatystoma corruscans) arraçoados com diferentes níveis de proteína e energia. 2003. $140 \mathrm{f}$. Tese (Doutorado em Genética e Evolução) - Universidade Federal de São Carlos, São Carlos, 2003. 
10.BUDDINGTON, R. K.; KROGDAHAL, A.; BAKKEMCKELLEP, A. M. The intestine of carnivorous fish: structure and functions and the relations with diet. Acta Physiology Scandinavica, v. 638, p. 67-80, 1997.

11.LIQUORI, G. E.; MASTRODONATO, M.; ZIZZA, S.; FERRI, D. Glycoconjugate histochemistry of the digestive tract of Triturus carnifex (Amphibia, Caudata). Journal Morphology Histology, v. 38, n. 3, p. 191-199, 2007.

12.DOMENEGHINI, C.; ARRIGHIA, S.; RADAELLI, G.; BOSIA, G.; VEGGETTI, A. Histochemical analysis of glycoconjugate secretion in the alimentary canal of Anguilla anguilla L. Acta Histochemical, v. 106, n. 6, p. 477-487, 2005.

13.EVANS, J. J.; PASNIK, D. J.; PERES, H.; LIM, C.; KLESIUS, P. $\mathrm{H}$. No apparent differences in intestinal histology of channel catfish (Ictalurus punctatus) fed heat-treated and non-heattreated raw soybean meal. Aquaculture Nutrition, v. 11, n. 2, p. 123-129, 2005.

14. ROMARHEIM, O. H.; ZHANG, C.; PENN, M.; LIU, Y. J.; TIAN, L. X.; SKREDE, A.; KROGDAHL, A.; STOREBAKKEN, T. Growth and intestinal morphology in cobia (Rachycentron canadum) fed extruded diets with two types of soybean meal partly replacing fish meal. Aquaculture Nutrition, v. 14, n 2, p. 174-180, 2008.

15. STATICAL ANALISYS SYSTEM. (SAS). User's guide: statistic. Versão 6.08. 4. ed. Cary: Institute, SAS, 1999.

16.KUBITZA, F. Qualidade da água no cultivo de peixes e camarões. Piracicaba: Degaspari, 2003.

17.FAGBENRO, O. A.; JAUNCEY, K.; HAYLOR, G. Nutritive value of diets containing dried lactic acid fermented fish silage and soybean meal for juvenile Oreochromis niloticus and Clarias garipinus. Aquatic Living Resource, v. 7, n. 2, p. 79-85, 1994.

18. OSTASZEWSKA, T.; DABROWSKI, K.; PALACIOS, M. E.; OLEJNICZAK, M.; WIECZOREK, M. Growth and morphological changes in the digestive tract of rainbow trout (Oncorhynchus mykiss) and pacu (Piaractus mesopotamicus) due to casein replacement with soybean proteins. Aquaculture, v. 245, n. 1/4, p. 273-286, 2005.

19.SCHUCHARDT, D.; VERGAR, J. M.; FERNANDEZPALACIOS, H.; KALINOWSKI, C. M.; HERNANÁNDEZCRUZ, C. M.; IZQUIERDO, M. S.; ROBAINA, L. Effects of different dietary protein and lipid levels on growth feed utilization and body composition of red porgy (Pagrus pagrus) fingerlings. Aquaculture Nutrition, v. 14, n. 1, p. 1-9, 2008.

20.TAKASHIMA, F; HIBIYA, T. An atlas of fish histology: normal and pathological features. 2. ed. Tokio: Kondansha Ltda, 1995. 195 p.

21. RUNGRUANGASK, K.; UTNE, F. Effect of different acidified wet feeds on protease activities in the digestive tract and on the growth rate of rainbow trout (Salmo gairdneri Richarson). Aquaculture, v. 22, p. 67-79, 1981.

22.HANSEN, A. C.; ROSENLUND, G.; KARLSEN, O.; OLSVIK, P. A.; HEMRE, G. I. The inclusion of plant protein in cod diets, its effects on macronutrient digestibility, gut and liver histology and heat shock protein transcription. Aquaculture Research, v. 37, n. 8, p. 773-784, 2006.

23.REOPEREZ, J.; TORTUERO, F.; RODRÍGUEZ, M. L.; FERNÁNDEZ, E. Efecto de la alimentación com harina de soja sometida a distintos tratamientos sobre el crescimento y morfología intestinal del lechon. Archivos de Zootecnia, v. 42, p. 125-135, 1993.

24.KOPOOR, B. G.; SMITH, H.; VERIGHINA, I. A. The alimentary canal and digestion in teleostets. Advanced Marine Biology, v. 13, p. 109-139, 1975.

25.TIBBETTS, I. R. The distribution and function of mucous cells and their secretions in the alimentary tract of Arrhamphus sclerolepis krefftii. Journal of Fish Biology, v. 50, n. 4, p. 809820, 1997.

26.SANTOS, C. M.; DUARTE, S.; SOUZA, T. G. L.; RIBEIRO, T. P. Histologia e caracterização histoquímica do tubo gastrintestinal de Pimelodus maculatus (Pimelodidae, Siluriformes) no reservatório de Funil, Rio de Janeiro, Série Zoologia, v. 97, n. 4, p. 411-417, 2007. 